\title{
Phase Formation in Electrodeposited Cu-Zn Alloy Films Produced from Ultrasonicated Solutions
}

\author{
K. YURDAL* AND İ.H. KaRAHAN \\ Mustafa Kemal University, Physics Department, Hatay, Turkey
}

\begin{abstract}
Thin film brass alloys were galvanostatically electrodeposited from non-cyanide citrate solutions. Aqueous sulphate solutions were used as deposition medium. It was aimed to understand the effect of ultrasonication of the solutions before electrodeposition process. Ultrasonication was not applied during deposition. This method was utilized to change solution characteristics, by applying high energy via cavitation mechanism, which would result in changes in resultant film properties. X-ray diffraction technique was used to investigate phase formation in samples. Moreover X-ray diffractograms were also used to calculate grain size values. $\mathrm{Cu}$ and $\mathrm{Zn}$ elements were codeposited successfully to form brass alloys. When phase formations in the samples were compared to each other, it was concluded that although there are small differences between X-ray diffractograms of samples, ultrasonic treatment before electrodeposition is not an effective way to alter phase characteristics of CuZn alloy samples, since all samples have shown similar X-ray diffraction graphs. Grain size is found to get smaller with presence of ultrasonication, extending ultrasonication time caused only small random changes in grain size.
\end{abstract}

DOI: 10.12693/APhysPolA.132.1091

PACS/topics: 81.05.Bx, 68.35.bd

\section{Introduction}

CuZn alloys find a wide range of applications in industry, both in bulk and thin film forms. These alloys have good mechanical properties, as well as good corrosion resistance. Some of the applications include corrosion protection, use as substrate material, interlayer for adhesion and decorative purposes [1-9]. In addition $\mathrm{Cu}$ and its alloys are important materials for many research areas $[10-12]$.

Another important property of CuZn alloys system is shape memory effect, which can be described as material ability to change shape by heating, due to martensiteaustenite phase transformation. Some other materials also show shape memory effect, including NiTi [13]. Under certain conditions shape memory materials can change shape by cooling as well, and can make cycles between different shapes [14], which brings possibility for them to be used in actuator applications, with high actuation forces. This shape change also changes some other material properties, which can be utilized in sensor applications [15]. Thin film shape memory materials are candidates to be used in micro-size applications and MEMS.

When materials are to be used in industrial applications, consistency and versatility are two key factors. In other words, materials must be consistently produced for quality concerns. Moreover, material properties must be well understood so that modifications can be made in material characteristics, to adapt to new applications. This can be achieved by extending research of materials. For example type and amount of phases, grain size and shape

*corresponding author; e-mail: kaganyurdal@hotmail.com distribution, internal stress, tensile stress, hardness, surface morphology are only some of the material properties that show changes depending on fabrication process.

Thin and thick films can be produced by many different methods [16-20]. Electrodeposition or electrochemical deposition is a simple but advantageous technique of fabrication of thin and thick films. It simply utilizes an electrochemical cell with an anode and a cathode. By applying an electric potential, ions in the solution are cathodically deposited onto substrate, which acts as anode. Electrodeposition provides versatility in fabrication. Deposition can be made under different conditions, such as constant current or constant potential. Electrodeposition process does not require vacuum.

There are several studies on CuZn film fabrication, some of which refer to shape memory effect [21-24]. There are many studies on use of ultrasound in electrodeposition of metallic materials and composites. For example Tudela et al. reported ultrasound assisted electrodeposition of nickel. They reported that presence of ultrasound caused preferred crystal orientation.

Grain refinement, together with work-hardening, produced harder $\mathrm{Ni}$ films [25]. Kim et al. used ultrasonic treatment in $\mathrm{Cu} / \mathrm{Al}_{2} \mathrm{O}_{3}$ nanocomposite thin film electrodeposition. They reported that ultrasound provides reduced agglomeration of nanoparticles and resulted in a finer grained $\mathrm{Cu}$ matrix and better mechanical properties [26].

This study focuses on phase formation in electrodeposited CuZn films. Type and concentration of complexes formed in solutions depend on many factors, such as acidity, temperature, ion concentration etc. When equilibrium complexes are changed, deposition mechanism also changes, which consequently results in different film properties. Aim of this study was to understand up to what extend ultrasonication can cause formation of different films, by changing solution properties via high energy ca- 
vitation and/or mixing. Phase formation was investigated using X-ray diffraction (XRD) technique. Grain size values were also calculated using XRD diffractograms.

\section{Experimental}

Electrodeposition of $\mathrm{Cu}$ and $\mathrm{Zn}$ was carried out simultaneously to form brass alloys using a PARSTAT 2273 galvanostat/potentiostat. Deposition was performed under constant current density of $15 \mathrm{~mA} / \mathrm{cm}^{2}$ for $1 \mathrm{~h}$, at ambient temperature, without stirring. Aluminum plates with dimensions of $2 \times 2 \mathrm{~cm}^{2}$ were used as substrates. Substrates were cleaned and activated by dipping into $1 \mathrm{M} \mathrm{NaOH}$ solution and rinsing with distilled water.

Platinum wire was used as the counter electrode. Experimental grade chemicals and distilled water were used in solution preparation. $0.06 \mathrm{M} \mathrm{CuSO}_{4} \cdot 5 \mathrm{H}_{2} \mathrm{O}$ and $0.1 \mathrm{M}$ $\mathrm{ZnSO}_{4} \cdot 7 \mathrm{H}_{2} \mathrm{O}$ were used as ion sources. $0.5 \mathrm{M}$ Trisodium citrate dihydrate (TSC Dihydrate) was used as complexing agent. Solution $\mathrm{pH}$ was set to 5.8. Solutions were ultrasonicated before electrodeposition by dipping ultrasound source directly into solution. Ultrasonication time was 5 to 60 minutes. A Hielscher UP 200S ultrasonicator was used at a cycle time of 0.5. A non-ultrasonicated solution was taken as reference for comparison. Fabricated films were peeled off from substrates for XRD examination. A Rigaku Smartlab X-ray diffractometer was used. Samples are named based on ultrasonication period. For example U20 is the sample that was fabricated from 20 minute ultrasonicated solution.

\section{Results and discussion}

$\mathrm{X}$-ray diffraction is one of the most important tools in characterization of crystalline materials. It provides data about type and amount of phases existing in the material. Figures 1 and 2 show XRD graphs of fabricated samples. In each graph U0, which is the sample produced without ultrasonication, is given as the reference. By giving two separate graphs it was aimed to make the examination easier.

In these two graphs, the effect of ultrasonication can be seen from the comparison of ultrasonicated samples to non-ultrasonicated reference sample and to each other. U30 sample has curled and separated from the substrate during deposition, which probably affected film properties. In general, films tend to have some macro defects, like local curlings, probably due to high current and/or long deposition time.

When XRD graphs are examined, it is seen that main phase is $\mathrm{CuZn}-\beta$. CuZn- $\alpha$ is seen in some samples in small amounts. For some samples presence of $\mathrm{CuZn}-\alpha$ is questionable, because XRD peak associated with $\mathrm{CuZn-}$ $\alpha$ phase may or may not be overlapping with main peak of $\mathrm{CuZn}-\beta$ phase. Some samples show an undefined peak at around 27.5 degrees. There are some differences in $\alpha / \beta$ phase ratio between samples. Table I gives chemical compositions of samples obtained from MP-AES. Composition range is between $35-48$ at. $\% \mathrm{Cu}$.

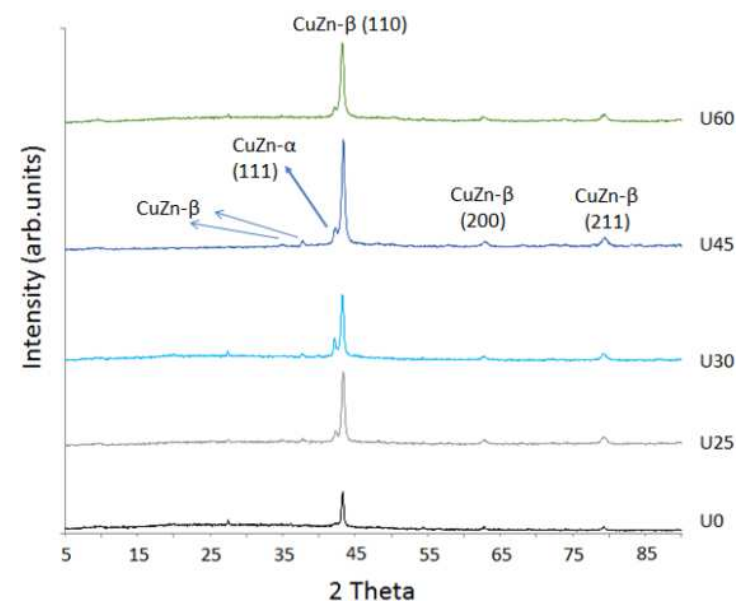

Fig. 1. Comparative XRD graphs of samples with 0 , $25,30,45$, and 60 minutes of ultrasonication.

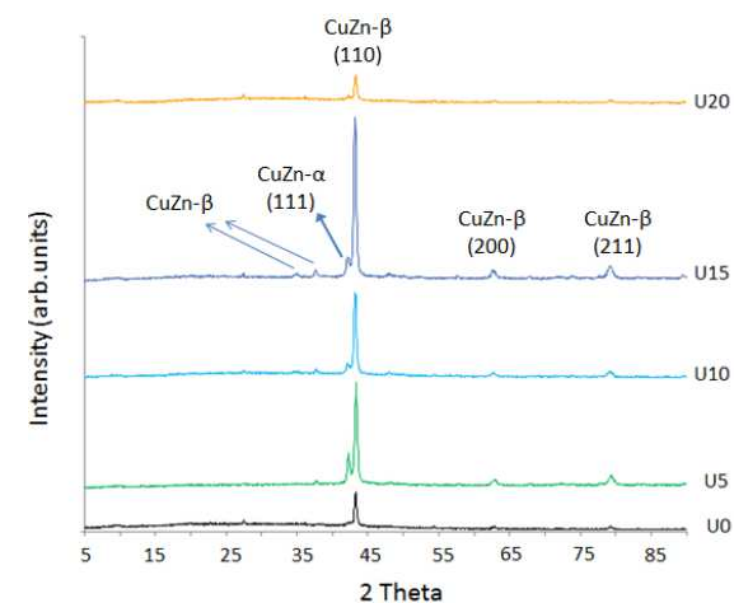

Fig. 2. Comparative XRD graphs of samples with 0 , $5,10,15$, and 20 minutes of ultrasonication.

Differences in XRD diffractograms are attributed to type and/or amount of complexes formed in deposition solutions. Difference in complex concentrations may be due to various reasons, such as acidity, temperature etc. In our case it is attributed to high energy ultrasonic treatment. Some researches reported type and amount of complexes formed in $\mathrm{Cu}$ and $\mathrm{Zn}$ solutions in which tri sodium citrate was used as the complexing agent.

One such study is reported by Sangmin Shin et al. They studied reduction potentials of $\mathrm{Cu}$ and $\mathrm{Zn}$ with and without citrate addition [27]. They studied reduction potentials and sodium citrate complexes, formed by these two elements. They reported that at $\mathrm{pH}$ values up to 4.5, $\mathrm{H}_{3} \mathrm{Cit}$ is abundantly present and because of its stability, it does not make complexes with metal ions. When solution acidity is increased, $\mathrm{H}_{2} \mathrm{Cit}^{-}, \mathrm{HCit}^{2-}$ and $\mathrm{Cit}^{3-}$ show peak values at around 4, 5.7, and 8, respectively. Beyond $\mathrm{pH}=8.5$ only $\mathrm{Cit}^{3-}$ is found to exist. They found that while $\mathrm{CV}$ of copper showed a reduction peak 
TABLE I

Chemical composition of thin films.

\begin{tabular}{c|c|c|c}
\hline \hline Sample & Zn $[\mathrm{ppm}]$ & $\mathrm{Cu}[\mathrm{ppm}]$ & At.\%Cu \\
\hline U0 & 4240 & 3380 & 44 \\
U5 & 3680 & 3010 & 45 \\
U10 & 6480 & 4950 & 43 \\
U15 & 6450 & 3490 & 35 \\
U20 & 4060 & 3120 & 43 \\
U25 & 6090 & 4980 & 45 \\
U30 & 9090 & 7440 & 45 \\
U45 & 9510 & 6870 & 42 \\
U60 & 7290 & 6660 & 48
\end{tabular}

at $-0.1 \mathrm{~V}$ (vs. $\mathrm{Ag} / \mathrm{AgCl}$ ) when no citrate was added, this peak disappeared and a new peak formed at $-0.8 \mathrm{~V}$ when sodium citrate was added.

In another study, S.J. Kim et al. reported that in $\mathrm{pH}$ interval of 5.8 - 6.5, depending on $\mathrm{Cu}$ concentration, $\left(\mathrm{Cu}_{2} \mathrm{Cit}_{2}(\mathrm{OH})_{2}\right)^{4-}$ is the most stable complex in solution and it suppresses direct reduction of $\mathrm{Cu}$ from the electrolyte [28].

Sangmin Shin et al. reported a similar study for zinc as well. They reported that at $\mathrm{pH}=4.7, \mathrm{Zn}(\mathrm{Cit})_{2}^{4-}$ is the most stable complex, but $\mathrm{H}_{2} \mathrm{Cit}^{2-}$ and $\mathrm{HCit}^{2-}$ ions coexist and the reduction of $\mathrm{Zn}$ is easier than at high $\mathrm{pH}$. Broad peaks at $-0.7 \mathrm{~V}$ were observed, which means that the reduction potential of $\mathrm{Zn}$ from citrate complex is increased. Thus, it can be concluded that trisodium citrate makes codeposition of copper and zinc possible by bringing their reduction potentials close to each other.

When XRD and composition data are evaluated together, it can be concluded that presence and application time of ultrasonication may make small changes both in composition and phase formation of samples. However, there is no net trend for phase formation or chemical composition. In other words, observed changes do not seem to provide a systematic way of controlling phase formation or chemical composition. Table II presents grain size values, calculated using the following formula [29]:

$$
D=\frac{0.9 \lambda}{\beta \cos \Theta} \text {. }
$$

TABLE II

Calculated grain size values.

\begin{tabular}{c|c|c|c}
\hline \hline Sample & $2 \Theta$ & FWHM & Grain size $[\mathrm{nm}]$ \\
\hline U0 & 43.26 & 0.27 & 31.65 \\
U5 & 43.29 & 0.37 & 22.85 \\
U10 & 43.14 & 0.39 & 21.79 \\
U15 & 43.14 & 0.41 & 20.99 \\
U20 & 43.24 & 0.38 & 22.31 \\
U25 & 43.26 & 0.45 & 19.08 \\
U30 & 43.19 & 0.41 & 20.99 \\
U45 & 43.32 & 0.39 & 21.80 \\
U60 & 43.19 & 0.47 & 18.10
\end{tabular}

It is seen that grain sizes of all films are well below $100 \mathrm{~nm}$. Highest grain size is seen in non-ultrasonicated sample. All ultrasonicated samples have grain sizes around $20 \mathrm{~nm}$. Among them, U60 sample has the lowest grain size with $18.1 \mathrm{~nm}$. Presence of ultrasonication has decreased grain size, however, having longer periods of ultrasonication did not make so much difference.

\section{Conclusions}

CuZn alloy films were fabricated from aqueous citrate solutions, using sulphates of $\mathrm{Cu}$ and $\mathrm{Zn}$. TSC was used as a complexing agent. Main objective of the study was to examine the effect of ultrasonic treatment, which was applied before electrodeposition in time periods of 5 to 60 minutes. A detailed XRD investigation was made. It was seen that mainly CuZn-beta phase is present in all samples. CuZn-alpha phase is clearly present in some samples, for others it is not certain whether it was present or not, since its peak may or may not be overlapping with main peak of beta-phase at around 43 degrees. It was concluded that ultrasonication may cause some small changes in XRD graphs, however these changes could not show a proportionality dependence. Chemical compositions of samples are close to each other, being around 44 at. $\% \mathrm{Cu}$, with extremities of $35 \%$ and $48 \%$ for samples processed for 15 and 60 minutes, respectively. The most important difference was observed in the grain size. Non-ultrasonicated sample has bigger grain size than all ultrasonicated samples. Extending ultrasonication time caused only small changes.

\section{References}

[1] F.A. Lowenheim, Modern Electroplating, Wiley, New York 1974.

[2] A. Brenner, Electrodeposition of Alloys. Principles and Practice, Vol. 1, Academic Press, New York 1963.

[3] H. Strow, Metal Finishing Guidebook 99, 206 (2001).

[4] I.A. Carlos, M.R.H. de Almeida, J. Electroanal. Chem. 562, 153 (2004).

[5] F.B.A. Ferreira, F.L.G. Silva, A.S. Luna, D.C.B. Lago, L.F. Senna, J. Appl. Electrochem. 37, 473 (2007).

[6] R. Juskenas, V. Karpaviciene, V. Pakstas, A. Selskis, V. Kapocius, J. Electroanal. Chem. 602, 237 (2007).

[7] K.M. Ismail, R.M. Elsherif, W.A. Badawy, Electrochim. Acta 49, 5151 (2004).

[8] M. Hemmous, A. Layadi, A. Guittoum, L. Kerkache, N. Tiercelin, A. Klimov, V. Preobrazhensky, P. Pernod, Europ. Phys. J. Appl. Phys. 70, 10301 (2015).

[9] Kribalis, P.E. Tsakiridis, C. Dedeloudis, E.J. Hristoforou, J. Optoelectronics Adv. Mater. 8, 1475 (2006).

[10] A.S. Kadırbayeva, A.B. Bayeshov, Acta Phys. Pol. A 128, B-458 (2015).

[11] W. Laslouni, Z. Hamlati, M. Azzaz, Acta Phys. Pol. A 128, B-190 (2015). 
[12] W. Laslouni, M. Azzaz, Acta Phys. Pol. A 130, 112 (2016).

[13] S.U. Rehman, M. Khan, A. Nusair Khan, L. Ali, S.H. Imran Jaffery, Acta Phys. Pol. A 128, B-125 (2015).

[14] X.B. Ren, K. Otsuka, MRS Bull. 27, 115 (2002).

[15] Yongqing Fu, Hejun Du, Weimin Huang, Sam Zhang, Min Hu, Sens. Actuators A: Phys. 112, 395 (2004).

[16] P. Krulevitch, A.P. Lee, P.B. Ramsey, J.C. Trevino, J. Hamilton, M.A. Northrup, J. MEMS 5, 270 (1996).

[17] E. Makino, M. Uenoyama, T. Shibata, Sens. Actuator A: Phys. 71, 187 (1998).

[18] I.N. Qureshi, M. Shahid, A.N. Khan, Acta Phys. Pol. A 128, B-314 (2015).

[19] N. Syla, F. Aliaj, B. Dalipi, Acta Phys. Pol. A 130, 83 (2016).

[20] S. Kurtay, Acta Phys. Pol. A 128, B-90 (2015).

[21] D. De Filippo, A. Rossi, D. Atzei, J. Appl. Electrochem. 22, 64 (1992).
[22] I.A. Carlos, M.R.H. de Almeida, J. Electroanal. Chem. 562, 153 (2004).

[23] P. Fricoteaux, C. Rousse, J. Electroanal. Chem. 733, 53 (2014).

[24] N. Haberkorn, M. Ahlers, F.C. Lovey, Scripta Mater. 61, 821 (2009).

[25] I. Tudela, Y. Zhang, M. Pal, I. Kerr, T.J. Mason, A.J. Cobley, Surf. Coat. Technol. 264, 49 (2015).

[26] M. Kim, F. Sun, J. Lee, Y.K. Hyun, D. Lee, Surf. Coat. Technol. 205, 2362 (2010)

[27] Sangmin Shin, Chansu Park, Chiho Kim, Yangdo Kim, Sungkyun Park, Jae-Ho Lee, Curr. Appl. Phys. 16, 207 (2016).

[28] S.J. Kim, D.J. Duquette, J. Electrochem. Soc. 153, C417 (2006).

[29] B.D. Cullity, S.R. Stock, Elements of X-ray diffraction, 3rd ed., Prentice Hall, 2001. 